\title{
Slow arsenic poisoning of the contaminated groundwater users
}

\author{
${ }^{1 *}$ M. M., Uddin, ${ }^{2}$ A. K. M., Harun-Ar-Rashid, ${ }^{3}$ S. M., Hossain, ${ }^{3}$ M. A., Hafiz, ${ }^{3}$ K. Nahar and \\ ${ }^{3}$ S. H. Mubin \\ ${ }^{1}$ Department of Physics, Chittagong University of Engineering and Technology, Chittagong, Bangladesh \\ ${ }^{2}$ Department of Physics, University of Chittagong, Chittagong, Bangladesh \\ ${ }^{3}$ Institute of Nuclear Science and Technology, Atomic Energy Research Establishment, Dhaka, Bangladesh \\ Received 9 March 2006; revised 29 August 2006; accepted 7 September 2006; available online 1 October 2006
}

\begin{abstract}
This paper gives impact of Arsenic contaminated water on human health as well as overview of the extent and severity of groundwater arsenic contamination in Bangladesh. Scalp hair is the most important part of the human body to monitor the accumulation of this type of poison. Therefore, an experiment has been carried out by Neutron Activation Analysis (NAA) at Atomic Energy Research Establishment (AERE), Savar, Dhaka, Bangladesh on human hair of corresponding tube well water users of these areas to determine the total accumulation of arsenic to their body. Hair samples collected from the region where the groundwater was found highly contaminated with arsenic. The obtained results of arsenic concentration in the lower age $(\mathrm{Hb})$ categories of users (below 12 years of age users) is in the range of 0.33 to $3.29 \mu \mathrm{g} / \mathrm{g}(\mathrm{ppm})$ and that in the Hu categories (upper 12 years of age users) is 0.47 to $6.64 \mu \mathrm{g} / \mathrm{g}$ (ppm). Where as maximum permissible range is $1 \mathrm{ppm}$ certified from WHO. Results show that the peoples are highly affected where the groundwater is highly contaminated with arsenic and acts as the primary source of arsenic poisoning among the peoples of those areas. The results indicate that human population is affected with arsenic locally using the contaminated water for a long time.
\end{abstract}

Key words: Arsenic, groundwater, Bangladesh, gamma ray activity, neutron activation analysis, trace elements

\section{INTRODUCTION}

Arsenic is one of the most commonly studies trace elements as it is both toxic and carcinogenic (Nriago, 1994). It is reported that $40 \%$ of arsenic in human body comes from food chain (BIAM, 2002). Arsenic has been taken into account as a dangerous environmental pollution and detected as a serious health risk in many countries of the world, reported from Argentina, Mexico, Chile, USA, Taiwan, Mongolia, Thailand, Philippines, China, Japan, India, as well as Bangladesh (Akram, 1997, BGS, 2001 and SOES-DCH, 2000). The arsenic contamination is not only a health hazard for the people; it also affects the environment and creates social problems (Table 1). There are two main theories (Pyrite oxidation and oxyhydroxide reduction) as to how arsenic is released into the ground water.

*Corresponding author, Email: mohi@cuet.ac.bd

Tel.: +88031 714 947; Fax: +88031 714910

Toxic, naturally occurring arsenic species<smiles>O[AsH](O)O</smiles><smiles>O=[As](O)(O)O</smiles>

Arsenic III

Arsenic V

Metabolic by products of arsenic $\mathrm{V}$<smiles>C[As](=O)(O)O</smiles>

Monomethyl arsenic<smiles></smiles> 
Non-toxic species of arsenic in food products<smiles>C[As](C)(C)CCO</smiles>

Arsenocholine<smiles>C[As](C)(C)C=O</smiles>

Arsenocbetaine

\section{MATERIALS AND METHODS}

Study area

Feni district of Bangladesh is selected for this experiment. It has six upazila. Each upazila comprises of several Unions. Each Union has some 'blocks' (wards). In each 'blocks' there are some 'Villages'.

The mechanism is illustrated in Fig. 1.

Table 1: Arsenic polluted countries with affected population and main reason

\begin{tabular}{lllll}
\hline $\begin{array}{l}\text { Name of } \\
\text { the country }\end{array}$ & $\begin{array}{l}\text { Year of } \\
\text { pollution }\end{array}$ & $\begin{array}{l}\text { Population } \\
\text { affected } \\
\text { by arsenic }\end{array}$ & $\begin{array}{l}\text { Maximum range of } \\
\text { pollution (mg/L) }\end{array}$ & Main reason of pollution \\
\hline Argentina & $1938-81$ & 20,000 & $0.1-2.0$ & Natural soil pollution \\
Mexico & $1963-83$ & 200,000 & $0.1-0.5$ & Oxidation of arsenic bearing minerals \\
Chile & $1957-69$ & 130,000 & $0.8-1.3$ & River cutting through arsenic bearing formation \\
USA & $1972-82$ & $3,000,000$ & $0.045-0.092$ & Oxidation of pyrite, reduction of ferric oxide, etc. \\
Taiwan & $1961-85$ & 100,000 & $>0.05$ & Oxidation of pyrite \\
Mongolia & $1962-89$ & 1,774 & $>0.05$ & Over-irrigation \\
Thailand & $1987-98$ & 18,000 & $0.05-5.0$ & A tin mine \\
Philippines & $1992-95$ & 39 & - & Geothermal power plant \\
China & $1953-93$ & 1,546 & - & Use of coal as fuel \\
Japan & $1945-95$ & 217 & - & Metal and coal mine \\
India & $1978-98$ & 200,000 & $0.05-3.7$ & Over-exploitation of groundwater (pyrite oxidation) \\
\hline
\end{tabular}

(Akram, 1997; BGS, 2001 and SOES-DCH,2000)

Table 2: Statistics of Arsenic contamination with affected areas and population in Bangladesh

\begin{tabular}{lll}
\hline Parameter & BGS (1999) & SOES-DCH (2000) \\
\hline Total area of Bangladesh & $147,570 \mathrm{~km}^{2}$ & $147,570 \mathrm{~km}^{2}$ \\
Area of affected districts & $134,275 \mathrm{~km}^{2}$ & $112,407 \mathrm{~km}^{2}$ \\
Total population of Bangladesh & $29.6 \mathrm{~mL}$ & $129.6 \mathrm{~mL}$ \\
Population of affected districts & $128.4 \mathrm{~mL}$ & $93.5 \mathrm{~mL}$ \\
Total districts in Bangladesh & 64 & 64 \\
Surveyed districts & 61 & 64 \\
Districts having arsneic above & 61 & 47 \\
max. permissible limit & & 357 \\
affected thana & 465 & 222 \\
affected thana surveyed & 411 & 147 \\
having arsenic $>0.05 \mathrm{mg}$ & 270 & $46.2 \mathrm{~mL}$ \\
exposed population & $80.1 \mathrm{~mL}$ & $25 \mathrm{~mL}$ \\
Population who drink & $21 \mathrm{~mL}$ & \\
water with arsenic $>0.05 \mathrm{mg} / \mathrm{L}$ & & \\
\hline
\end{tabular}

Table 3: Comparison of arsenic concentration determined in the standard reference material As (NIST, USA), Coal Fly Ash, Pond Sediment (NIST, USA), and SL-1, Soil-7, (IAEA) with the certified value

\begin{tabular}{|c|c|c|c|c|}
\hline Standard Sample & Element & $\begin{array}{c}\text { Experimental value } \\
\mu \mathrm{g} / \mathrm{g}(\mathrm{ppm})\end{array}$ & $\begin{array}{c}\text { Certified value } \\
\mu \mathrm{g} / \mathrm{g}(\mathrm{ppm})\end{array}$ & $\begin{array}{c}\text { Deviation } \\
\% \\
\end{array}$ \\
\hline Soil-7 & As & $12.8 \pm 0.7$ & $13.4 \pm 0.9$ & 4.4 \\
\hline SL-1 & As & $29.7 \pm 1.64$ & $27.6 \pm 2.9$ & 6.8 \\
\hline As standard & As & 19.6 & 20 & 2 \\
\hline Coal fly ash & As & $140.5 \pm 10$ & $145 \pm 15$ & 3.2 \\
\hline Pond sediment & As & $12.4 \pm 1.29$ & $12 \pm 2$ & 3.3 \\
\hline
\end{tabular}


Slow arsenic poisoning of...

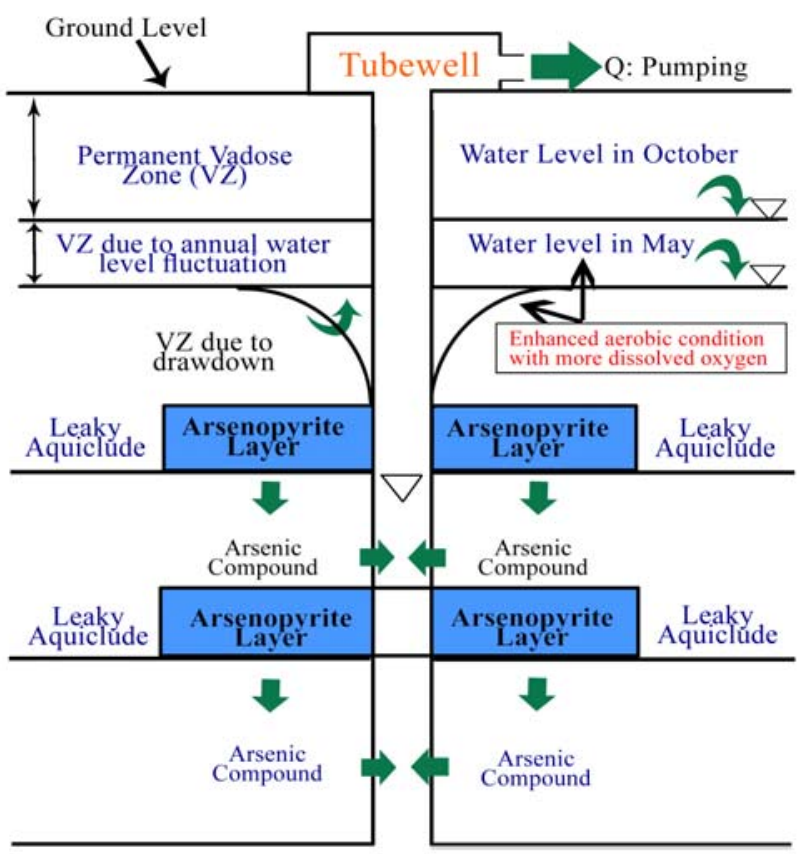

Fig. 1: Aerobic condition in groundwater around a tubewell

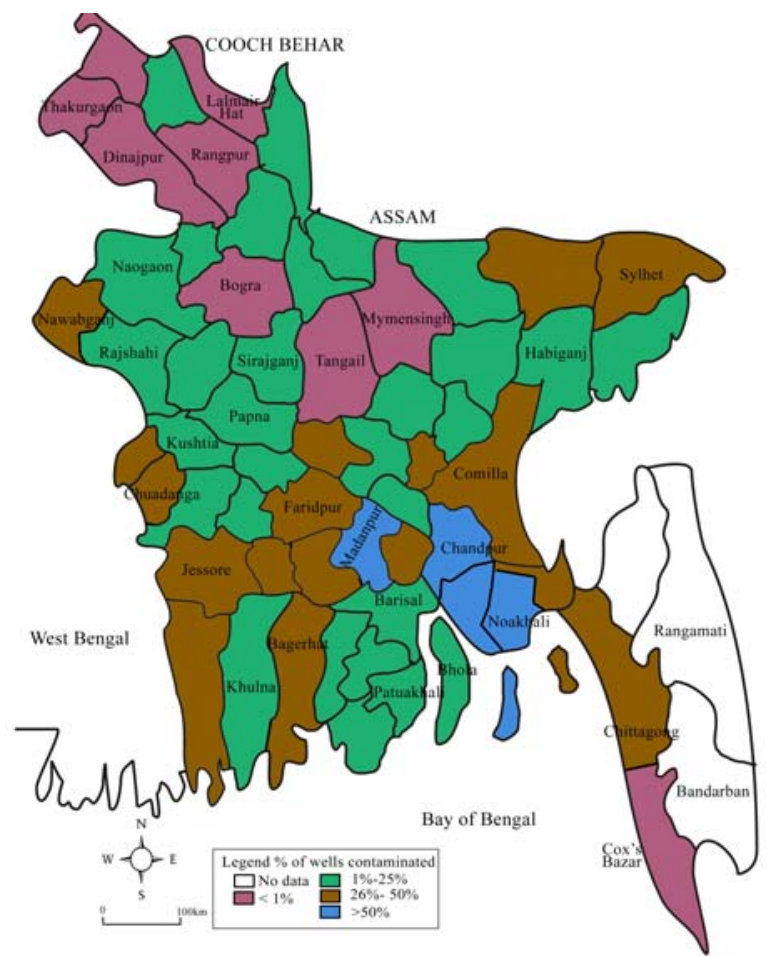

Fig. 2: Groundwater arsenic contamination in different districts of Bangladesh based on compilation of field and laboratory test data 


\section{Sample collection}

Hair samples were collected from the tube well water users. Hair samples of the water users of this district have been categorized into two: below 12 years of ages and upper 12 years and are coded as $\mathrm{Hb}$ and $\mathrm{Hu}$, respectively. Before, collecting samples, scissor was cleaned by acetone to avoid the others contamination.

\section{Sample preparation}

Hair samples were transferred from polyethylene bag to the Petri dish. In order to clean hair samples properly, samples were washed and dried in the following ways;

i) Acetone and dried naturally

ii) Deionized water and then dried

iii) Again by acetone and dried

The dried clean hairs were cut into small pieces. Four types of standard reference materials were used for the analysis of two sets of hair samples (a total of 30 samples) supplied by National Institute of Standard and Technology (NIST). Whereas the first set was analyzed using the International Atomic Energy Agency (IAEA) certified reference materials Soil-7 and SL-1, the second set was analyzed using coal fly ash and pond sediment. About $100 \mathrm{mg}$ hair was taken into the bullet type irradiation vial. The identification of the sample was put at the outer surface of the vial and heat-sealed.

\section{Irradiation and data counting}

$\mathrm{Al}-\mathrm{Au}$ Flux monitors were used between the two set of samples to determine neutron flux gradients. The samples and standards were irradiated in the $3 \mathrm{MW}$ TRIGA MARK-II research reactors at the Atomic Energy Research Establishment (AERE), Savar, and Dhaka, Bangladesh. The irradiation was performed with neutron flux of $1.52 \times 10^{13} \mathrm{n} / \mathrm{cm}^{2} / \mathrm{sec}$ at a power level of $500 \mathrm{~kW}$ for $20 \mathrm{~min}$. using Dry Central Thimble (DCT) facility, counting time for hair was $3600 \mathrm{sec}$. Below Fig. 3 show the irradiation capsule, get ready for irradiation. After irradiation completes the samples, standards and flux monitors were counted with a high purity germanium detector coupled with a personal computer based S-100 Multi Channel Analyzer (MCA) master board packages. The energy spread in multichannel analyzer was adjusted to $0-1500 \mathrm{keV}$ over 4096 channels. Gamma ray counting were performed for samples and standards after a decay time of 1-2 day, with a measuring time of 500-3600s for the determination of As $\left[{ }^{75} \mathrm{As}(\mathrm{n}, \gamma){ }^{76} \mathrm{As} \rightarrow{ }^{76} \mathrm{Se}\left(\mathrm{t}_{1 / 2}=26.3 \mathrm{~h} ; \mathrm{E}_{\gamma}=559.1 \mathrm{keV}\right)\right]$. Countings for flux monitors were performed with a measuring time of 60s for the determination of $\mathrm{Au}$ $\left[{ }^{197} \mathrm{Au}(\mathrm{n}, \gamma){ }^{198} \mathrm{Au}\left(\mathrm{t}_{1 / 2}=2.35 \mathrm{~d} ; \mathrm{E}_{\gamma}=411.6 \mathrm{keV}\right)\right]$. The dead time was kept below 7\% during counting for both samples and standard.

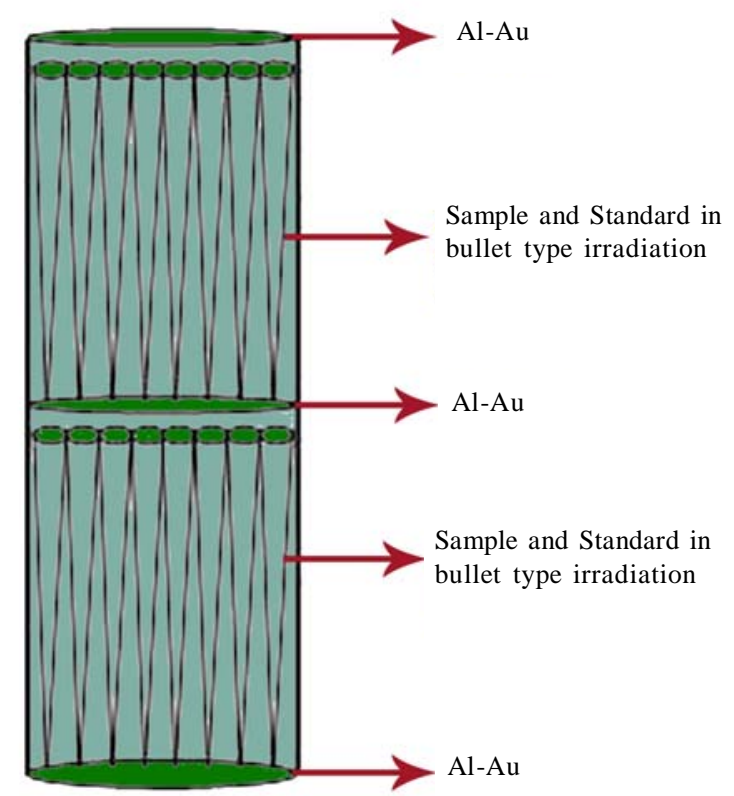

Fig. 3: An irradiation capsule gets ready for irradiation. 


\section{Calculation of arsenic concentration}

For the calculation of concentrations, the peakgr10 software package was used. Concentratrions calculation were also performed manually by the following activation equation

Weight of element "a" in sample Weight of element "b" in std.

$$
=\frac{\mathrm{A}_{\mathrm{x}^{*}} \text { in sample } \mathrm{e}^{+\lambda t \text { sample }}}{\mathrm{A}_{\mathrm{x}^{*}} \text { in } \cdot \mathrm{e}^{+\lambda \mathrm{tstd} .}}
$$

Where, ' $a$ ' and ' $b$ ' are the weight of the element in the sample and standard respectively. $\mathrm{A}_{\mathrm{x}^{*}}$ is the activity in sample and standard (Laul 1979).Both the program and manual calculations gave the consistent results.

Accuracy of the analysis and the total uncertainty

Quality Assurance (QA) test is performed to investigate the reliability of the analysis by measuring arsenic concentration level in standard reference materials As (NIST, USA), coal fly ash, SL-1 and Soil-7 (IAEA) relative to primary standard of arsenic. The analytical results for certified reference materials are given in the table below. The experimental results are within $10 \%$ deviation, which is a good agreement with the certified value. This deviation was achieved due to poor counting statistics. Uncertainties of the samples were calculated according to the 1993 ISO guide and were added to the uncertainty in the measurement (Kuèera, et al., 1999). Table 3 Shows that Comparison of arsenic concentration determined in the standard reference material As (NIST, USA), Coal Fly Ash, Pond Sediment (NIST, USA), and SL-1, Soil-7, (IAEA) with the certified value.

\section{RESULTS}

The obtained results of arsenic concentration in the lower age $\mathrm{Hb}$ (below 12 years of age users) categories of users is in the range of 0.33 to $3.29 \mu \mathrm{g} / \mathrm{g}$ and that in the Hu (upper 12 years of age users) categories is in the range of 0.47 to $6.64 \mu \mathrm{g} / \mathrm{g}$. Arsenic detected in the samples $\mathrm{Hb}-1$ to $\mathrm{Hb}-6$ is in the range of 0.13 to $3.29 \mu \mathrm{g} /$ $\mathrm{g}$, where as arsenic in corresponding upper age users samples Hu-1 to Hu-6 is in the range of 1.48 to $6.64 \mu \mathrm{g} /$ $\mathrm{g}$. Arsenic in the samples $\mathrm{Hb}-7$ to $\mathrm{Hb}-14$ is in the range of 0.33 to $1.2 \mu \mathrm{g} / \mathrm{g}$, where as in corresponding upper age users samples $\mathrm{Hu}-7$ to $\mathrm{Hu}-14$ is in the range of 0.24 to $5.75 \mu \mathrm{g} / \mathrm{g}$. Maximum permissible range of arsenic in the human scalp hair is $1 \mu \mathrm{g} / \mathrm{g}$ certified by WHO.

\section{DISCUSSION AND CONCLUSION}

In this study, arsenic is detected to the human scalp hair samples for both the $\mathrm{Hb}$ and $\mathrm{Hu}$ categories. It is shown in Fig. 4 that arsenic is detected in human scalp hair for both the $\mathrm{Hb}$ (below 12 years users) and $\mathrm{Hu}$ (Upper 12 years users) categories, but from the above Figs it is shown that the under 12 years old peoples (Hb) are less affected compared to the more than 12 years old peoples (Hu). From Fig. 4, it is shown that the samples Hb-1 to Hb-6, which were collected from the areas of the Sonagazi, Dagon bhuiyan Upazilas of the district, show and lower accumulation of arsenic where as from Fig. 4, the samples Hu-1 to Hu-11 show

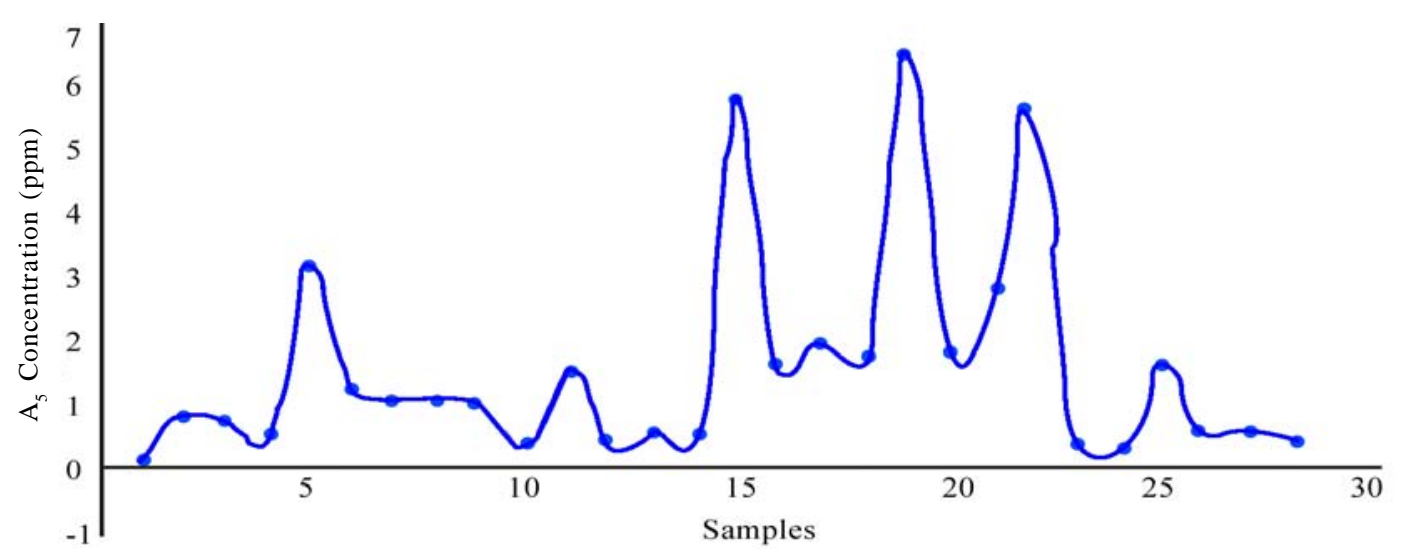

Fig. 4: Arsenic Concentration in human hair scalp hair 
the higher accumulations. Hair samples $\mathrm{Hb}-7$ to $\mathrm{Hb}-12$ show very high accumulation of arsenic and the groundwater in the corresponding areas were found highly contaminated by arsenic and is in the range (110-190) mg/L (Uddin, et al., 2005). Hair samples Hb13 to $\mathrm{Hb}-14$ in the under 12 years category show the lower accumulations of arsenic (0.45-0.63) $\mu \mathrm{g} / \mathrm{g}$ which is justified to the corresponding lower arsenic found in the groundwater in the respective areas and is in the range (5-43) $\mu \mathrm{g} / \mathrm{g}$ (Uddin, et al., 2005). Results were obtained from the experiment that the human hair samples, the fewer than 12 years old users $(\mathrm{Hb})$ are less affected compared to the more than 12 year old users (Hu).

Therefore, it is concluded that higher values of arsenic in hair samples were due to the longtime accumulation of arsenic through the uses of contaminated groundwater. Results show that the ground water is contaminated with arsenic and acts as the primary source of arsenic poisoning among the peoples of those areas. The results indicate that human population is affected with arsenic locally using the contaminated water for a long time.

\section{ACKNOWLEDGEMENT}

This work was partly supported by National Institute of Standard and Technology (NIST), USA and International Atomic Energy Agency (IAEA).

\section{REFERENCE}

Akram, S., (1997). Arsenic problem. The daily sangbad of Bangladesh.

BGS, (1999). Ground water Studies for Arsenic Contamination in Bangladesh. Main Report and Supplemental, Dhaka, British Geological Survey, Bangladesh and Mott MacDonald International Ltd., United Kingdom: Government of the Peoples Republic of angladesh, Ministry of Local Government, Rural Development and Cooperatives, Department of Public Health Engineering. 1-3.

BGS (British Geological Survey), (2001). Ground water studies of arsenic contamination in Bangladesh. Phase 2, Nottingham, Britain.(British Geological Survey)

BIAM, (2002). $4^{\text {th }}$ inernational conference on Arsenic contamination of underground water in Bangladesh cause, Effect and Remedy, Dhaka.

Karim, M. A., Komori, Y. and Alam, M., (1997). Subsurface Arsenic Occurrence and Depth of Contamination in Bangladesh. J. Environ. Chem., 7 (4), 783-792.

Kucera, J., Bode, P., and Stepanek, V., (1999). The 1993 ISO guide to the expression of uncertainty in measurement applied to NAA. J. Rad. Ana. Nuc. Chem., 245 (1), 15.

Laul, J. C., (1979). Atomic Energy Review. 17, 3.

Nriago, J. O., (1994). Arsenic in the environment. 1, 52.

SOES-DCH. (2000). Groundwater Arsenic Contamination in Bangladesh. A. Summary of 239 days field survey from August 1995 to February 2000, B. Twenty-seven days detailed field survey information from April 1999 to February 2000. School of Environmental Studies, Jadavpur University, Calcutta 700 032, India and Dhaka Community Hospital, Dhaka 1217, Bangladesh.

Uddin, M. M., Harun-Ar-Rashid, A. K. M., and Hossain, S. M., (2005). Precise measurement of Arsenic in the Contaminated Groundwater of Bangladesh. Res. J. Mech. Eng., 5, 15-19. 


\section{AUTHOR(S) BIOSKETCHES}

Uddin, M. M., B.Sc., M.Sc., is a lecturer in the Department of Physics, Chittagong University of Engineering and Technology, Chittagong, Bangladesh. Now he is pursuing M.Phil at CUET, Chittagong, Bangladesg. Email: mohi@cuet.ac.bd

Harun-Ar-Rashid, A. K. M., M.Sc., Ph.D., is an Associate Professor in the Department of Physics, University of Chittagong, Chittagong, Bangladesh. Now he is pursuing Post-Doctorate research at Canada. Email: harashid.phy@gmail.com

Hossain, S. M., M.Sc., Ph.D., is a Principal Scientific Officer (PSO), Institute of Nuclear Science and Technology at Atomic Energy Research Establishment, Dhaka, Bangladesh.

Email: syed9495@hotmail.com

Hafiz, M. A., M.Sc., is a Senior Scientific Officer (SSO) Institute of Nuclear Science and Technology at Atomic Energy Research Establishment, Dhaka, Bangladesh. Email: hafizam@yahoo.co.in

Nahar, K., M.Sc., is a Scientific Officer (SO) Institute of Nuclear Science and Technology at Atomic Energy Research Establishment, Dhaka, Bangladesh Email: sislam_psa@yahoo.co.in

Mubin, S. H., MSc, is a Scientific Officer (SO) Institute of Nuclear Science and Technology at Atomic Energy Research Establishment, Dhaka, Bangladesh. Email: mubinsh@hotmail.com

\section{This article should be referenced as follows:}

Uddin, M. M., Harun-Ar-Rashid, A. K. M., Hossain, S. M., Hafiz, M. A., Nahar, K. and Mubin, S. H., (2006). Slow arsenic poisoning of the contaminated groundwater users. Int. J. Environ. Sci.

Tech., 3 (4),447-453 